\title{
Postgenomic taxonomy of human ureaplasmas - a case study based on multiple gene sequences
}

\author{
Fanrong Kong and Gwendolyn L. Gilbert
}

Correspondence

Gwendolyn L. Gilbert

lyng@icpmr.wsahs.nsw.gov.au

\section{INTRODUCTION}

There have been two recent major developments that affect our understanding of human ureaplasmas. Firstly, the full genome sequence of Ureaplasma parvum (previously known

\footnotetext{
Published online ahead of print on 2 July 2004 as DOI 10.1099/ ijs.0.63073-0.

The GenBank/EMBL/DDBJ accession numbers for the sequences described in this article are: rRNA gene cluster, AF272599AF272604, AF073446-AF073459, AF059322-AF059335 and AF272605-AF272630; tuf, AF270758-AF270770; urease gene clusters, AF085720-AF085733; mba, AF055358-AF055367 and AF056982-AF056984.

Comparisons of two $U$. parvum serovar 3 rRNA operons (Fig. A), U. urealyticum serovar 8 and U. parvum serovar 3 rRNA operon 1 and operon 2 DNA sequences (Fig. B), U. urealyticum serovars 8 and 13 and $U$. parvum serovar 3 EF-Tu gene (tuf) DNA and amino acid sequences (Fig. C), and U. urealyticum serovar 8 (upper line) and $U$. parvum serovar 3 (lower line) urease gene cluster sequences (Fig. D), and a comparison of interspecies heterogeneity of DNA and amino acid sequences of the urease gene clusters of $U$. parvum and $U$. urealyticum (Table A) are available as supplementary material in IJSEM Online.
}

as Ureaplasma urealyticum) serovar 3 was released in 2000 (GenBank accession no. NC_002162) (Glass et al., 2000). Secondly, the taxonomy of human Ureaplasma species changed in 2002 (Robertson et al., 2002), when the two former $U$. urealyticum biovars were given full species status, as $U$. parvum (previously biovar parvo or biovar 1) and $U$. urealyticum (previously biovar $\mathrm{T} 960^{\mathrm{T}}$ or biovar 2 ) (Robertson et al., 2002).

It is now accepted that a decision to create a new species should be based on many independent phenotypic and genotypic characteristics - the theory of 'polyphasic taxonomy' (Vandamme et al., 1996). However, molecular methods and genome-based criteria have become more accessible and attractive (Gürtler \& Mayall, 2001; Stackebrandt et al., 2002). DNA-DNA hybridization showing less than $70 \%$ homology between whole genomes is accepted as the most definitive criterion or 'gold standard' for separate prokaryote species (Murray \& Schleifer, 1994). The traditional $70 \%$ DNA-DNA hybridization value used to delineate genomic species was found to correspond to genome mispairings in the range $13-13 \cdot 6 \%$ or $0 \cdot 097-0 \cdot 104$ 
nucleotide substitutions per site (Mougel et al., 2002). Similarity of less than $97 \%$ in the $16 \mathrm{~S}$ rRNA gene is the most widely used practical alternative (Murray \& Schleifer, 1994), but these criteria may conflict and additional alternative targets are required (Pettersson et al., 2000; Dellaglio et al., 2004).

The two Ureaplasma species discussed herein exhibit many distinct phenotypic and genotypic properties (including DNA-DNA hybridization showing less than $70 \%$ homology), which support the change in taxonomy and fulfil the requirements of the polyphasic theory (Vandamme et al., 1996). However, continued use of the old single-species nomenclature in some recent publications (Daxboeck et al., 2003; Baier et al., 2003) is potentially confusing. To strengthen the case for acceptance and exclusive use of the new ureaplasma taxonomy (Robertson et al., 2002), we studied four 'core' genes/gene clusters - the rRNA gene cluster, EF-Tu gene (tuf), urease gene cluster and multiple-banded antigen gene $(\mathrm{mba})$ - of all 14 human ureasplasma serovars. These four regions were chosen because previous studies have shown that they were promising targets for study of the phylogeny of ureaplasmas and mycoplasmas (Kong et al., 1999b, 2000b; Kamla et al., 1996). In addition, we used this as a case study to help resolve some common problems with the use of sequence data to infer phylogeny and to support the establishment of new taxonomy (Ludwig et al., 1998).

\section{METHODS}

Bacterial strains. Reference strains of four $U$. parvum and ten $U$. urealyticum serovars, obtained directly from the American Type Culture Collection (ATCC), were the same as those used in our previous studies (Kong et al., 1999a).

Value of $U$. parvum serovar 3 genome in oligonucleotide primers design. The full genome sequence of $U$. parvum serovar 3 (Glass et al., 2000) greatly facilitated sequencing of the selected genes and gene clusters of the other three $U$. parvum and ten $U$. urealyticum serovars. For this study, we used the following steps. Firstly, to identify conserved regions, we compared known sequences of genes corresponding to our selected genes and gene clusters rRNA gene cluster, tuf and urease gene clusters - in other Mycoplasma species and Ureaplasma serovars (Fraser et al., 1995; Himmelreich et al., 1996; Neyrolles et al., 1996), in addition to $m b a$, which we and others have studied in detail previously (Zheng et al., 1995; Kong et al., 1999a). Based on the results, we designed primers and amplified target regions for sequencing. The target regions sequenced were: (a) the whole rRNA gene cluster, including a short region upstream of the 16S rRNA gene (for U. parvum serovars only), the $16 \mathrm{~S}$ rRNA gene, the 16S-23S rRNA intergenic spacer, the $23 \mathrm{~S}$ rRNA gene, the 23S-5S rRNA intergenic spacer, the $5 \mathrm{~S}$ rRNA gene and a short region downstream of the $5 \mathrm{~S}$ rRNA gene (see supplementary Figs A and B in IJSEM Online); (b) almost the full-length of tuf (see supplementary Fig. C in IJSEM Online); (c) the whole urease gene cluster, including short regions upstream of ureA-ureA-ureB-ureC-ureE-ureF-ureG-ureD and downstream of ureD (see supplementary Fig. D in IJSEM Online).

The amplification and sequencing primers used in the study are shown in Table 1. Most primers were used for both amplification and sequencing, but some (as inner sequencing primers) were used only for sequencing.
DNA preparation and PCR. These were performed as described previously (Kong et al., 1999b).

Sequencing and sequence analysis. The PCR products were sequenced as described previously (Kong et al., 2000b). All sites showing unexpected heterogeneity, such as those indicating rRNA gene inter-copy sequence variation and the unique heterogeneity site in serovar 13 tuf (see below), were sequenced at least twice, to confirm the results. When necessary, different PCR amplicons and/or inner sequencing primers were used for sequencing.

The initial sequencing results were analysed with the program Bestfit in the Comparison program group and then joined together to determine sequences of whole genes/gene clusters. The multiple sequence alignments were performed with the programs Pileup and Pretty from the Multiple Sequence Analysis program group. All of the programs/program groups are available in WebANGIS (http:// www1.angis.org.au/WebANGIS/), ANGIS (Australian National Genomic Information Service).

\section{RESULTS AND DISCUSSION}

\section{Advantages of sequencing multiple strains}

In this study, as in our previous study of $m b a$ (Kong et al., $2000 \mathrm{~b}$ ), we sequenced the three target genes/gene clusters for 13 ureaplasma serovars (excluding serovar 3 sequences from the full genome, which were used as reference). The advantages of this approach are: (i) since the genes/gene clusters are relatively conserved between serovars within each species, the results for different serovars help to confirm the accuracy of sequencing results (Clayton et al., 1995); and (ii) the results help to differentiate interspecies from intraspecies heterogeneity (Mygind et al., 1998).

A previous study showed that there is some intraserovar as well as interserovar/intraspecies and interspecies heterogeneity in $m b a$ (Knox et al., 1998). However, there is limited intraspecies heterogeneity in the other three gene regions studied and, even in $m b a$, intraspecies heterogeneity is much less than between species (Kong et al., 1999b). Therefore, a single reference strain of each serovar provides an example of each species to demonstrate interspecies heterogeneity, which was the focus of this study.

\section{Key characteristics of the 'core' genes}

Interspecies, intraspecies and inter-copy polymorphisms of the rRNA gene cluster. There was relatively little interspecies heterogeneity in $16 \mathrm{~S}$ and $23 \mathrm{~S}$ rRNA genes but considerably more in the two copies of the $5 \mathrm{~S}$ rRNA genes and the corresponding intergenic spacer regions (Table 2). In common with other targets studied, the intraspecies heterogeneities in these genes were minor and some were assumed to be due to inter-copy differences between duplicate copies (Table 2). Previous studies have shown sequence variation in duplicate copies of rRNA genes of other mollicutes (Pettersson et al., 1996). Analysis of the two copies of the rRNA gene cluster in $U$. parvum serovar 3 genome (GenBank accession no. AE002111 plus AE002112 and AE002127 plus AE002128) showed inter-copy heterogeneity between $16 \mathrm{~S}$ rRNA genes 
Table 1. Sequences of oligonucleotide primers used for sequencing three different genes/gene clusters

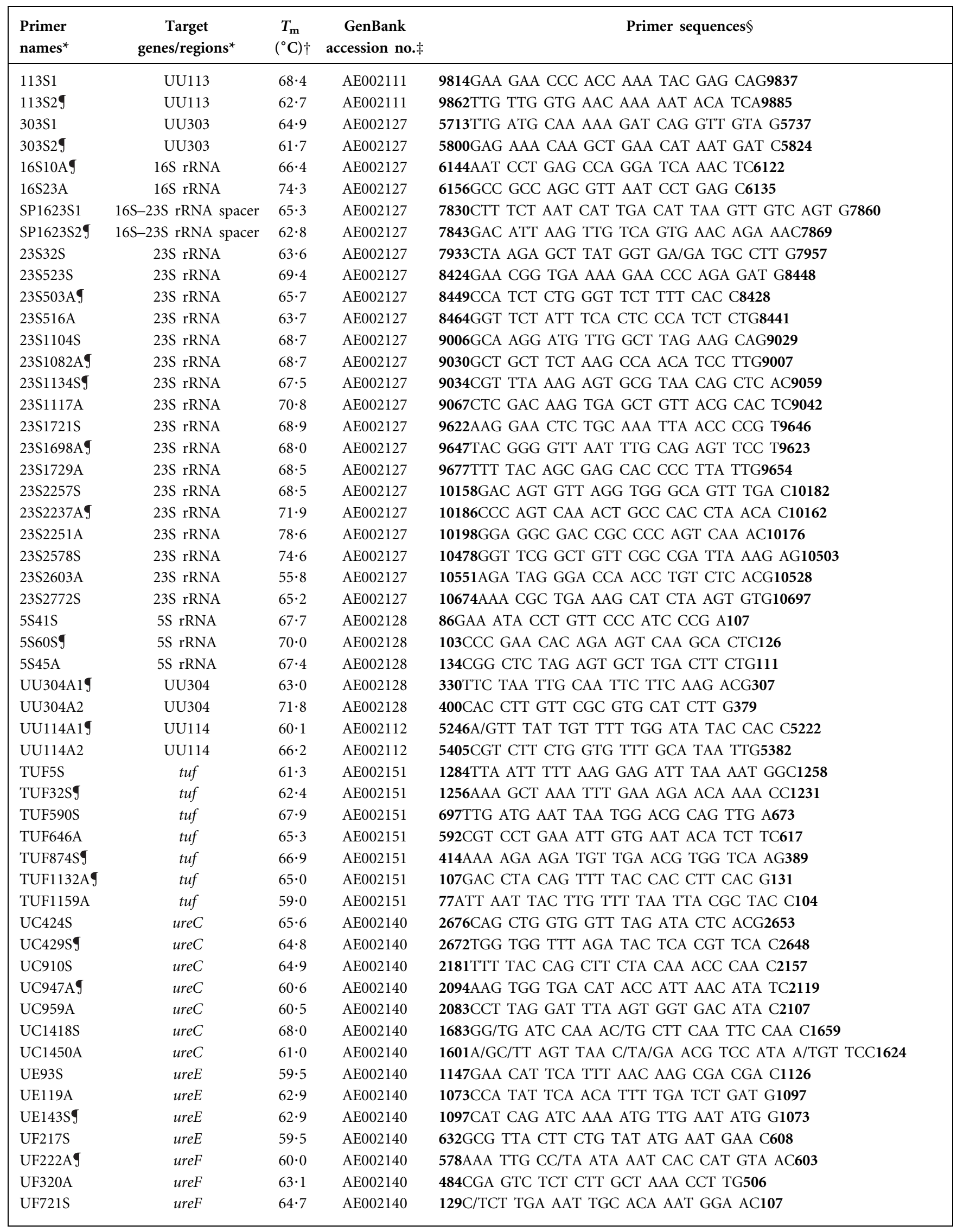


Table 1. cont.

\begin{tabular}{|c|c|c|c|c|}
\hline $\begin{array}{l}\text { Primer } \\
\text { names }\end{array}$ & $\begin{array}{c}\text { Target } \\
\text { genes/regions }{ }^{\star}\end{array}$ & $\begin{array}{c}T_{\mathbf{m}} \\
\left({ }^{\circ} \mathbf{C}\right) \dagger\end{array}$ & $\begin{array}{c}\text { GenBank } \\
\text { accession no. } \neq\end{array}$ & Primer sequences $\S$ \\
\hline UG3A & ureG & $62 \cdot 4$ & AE002139 & 11152CCT ACA CCA ATA ATT AAT GGT CTT TTC11178 \\
\hline UG475S & ureG & $63 \cdot 4$ & AE002139 & 10730GTT GAT TTA GCT CCT TAT GTT GGT G10706 \\
\hline UG451A 9 & ure $G$ & $63 \cdot 4$ & AE002139 & 10706CAC CAA CAT AAG GAG CTA AAT CAA C10730 \\
\hline UG499A & ure $G$ & $60 \cdot 6$ & AE002139 & 10655CTT TAT TAC CAC GTG ATT TTA ATG TAT C10682 \\
\hline UD332S & ureD & $59 \cdot 0$ & AE002139 & 10246CA/TG AA/GC AAC AC/TA CAA ATA TC/TA CA/GT TAG G10219 \\
\hline UD379A & ureD & $62 \cdot 0$ & AE002139 & 10147TTA AAT TGG/T GCA/G AAC/T TTT CCA TCT TC10172 \\
\hline UD841A & ureD & $62 \cdot 3$ & AE002139 & 9684CTT C/TTA TGG TTT TCG TAA AAT TAA A/TGG9710 \\
\hline UU427A19 & UU427 & $60 \cdot 4$ & AE002139 & 9446AAT AAA TTT TGC TAA AAA AGG CAT AC9471 \\
\hline UU427A2 & UU427 & $56 \cdot 5$ & AE002139 & 9330GT/CA/T GGT/C TTA AAA T/CTA ACA TCT ACA C9354 \\
\hline UU427A3 & UU427 & $63 \cdot 1$ & AE002139 & 9175CAT CAT CAA AAT CTT TAA TAC CAT CAT C9199 \\
\hline
\end{tabular}

${ }^{\star}$ Primers were named according to their target genes/regions, the $3^{\prime}$ end locations (the distance from the beginning of corresponding genes/ regions), and directions of primers (sense or antisense). In the target regions designated UU, the numbers indicate the number of the open reading frame (ORF) corresponding to that in the $U$. parvum genome sequence.

$\dagger$ The melting temperature $\left(T_{\mathrm{m}}\right)$ values were obtained from the primer synthesizer (Sigma-Aldrich).

$\ddagger$ All GenBank sequences were from the related sections of the full genome sequences of U. parvum serovar 3 (Glass et al., 2000).

$\S N u m b e r s$ represent the numbered base positions at which primer sequences start and finish (and correspond with those in GenBank). Letters behind a solidus $(/)$ indicate alternative nucleotides in different species/serovars, which were based on the comparison with the other related GenBank sequences.

SPrimers used only for sequencing; all the other primers were used for both PCR and sequencing.

(one site), 16S-23S rRNA intergenic spacer regions (two sites), 23S rRNA genes (four sites) and 5S rRNA genes (one site) but none in the 23S-5S rRNA intergenic spacer regions (Fig. A in IJSEM Online). In sequences of the corresponding genes of the other 13 serovars the result was ' $N$ ' (i.e. unknown or unidentifiable nucleotide) rather than 'A, T, C or G', at several sites, even after repeat sequencing or use of different amplification and sequencing primers. We assumed that most, if not all, of these were due to inter-copy polymorphisms (see Table 2 and supplementary Figs A and B in IJSEM Online) (Ueda et al., 1999). If these inter-copy polymorphisms were ignored, the intraspecies heterogeneity in rRNA gene clusters between the two human Ureaplasma species was very low. In future, the design of primers or probes or study of the phylogenetic relationships should take account of polymorphisms between multi-copy rRNA gene clusters (Gürtler, 1999).

Table 2. Comparison of interspecies, intraspecies and inter-copy heterogeneity in rRNA gene clusters of $U$. parvum and U. urealyticum

\begin{tabular}{|lcccc|}
\hline \multirow{2}{*}{ Genes/regions } & DNA & \multicolumn{2}{c|}{ Heterogeneity sites: N (\%) } \\
\cline { 3 - 5 } & length & Interspecies & U. parvum intraspecies & U. urealyticum intraspecies \\
\hline 16S rRNA gene & $1513 \dagger$ & $14(0 \cdot 93)$ & $2(1 \ddagger)$ & $2(1 \ddagger)$ \\
16S-23S rRNA gene spacer & 302 & $13(4 \cdot 3)$ & $2(2 \ddagger)$ & 0 \\
23S rRNA gene & 2903 & $26(0 \cdot 90)$ & $0(7 \ddagger)$ & 0 \\
23S-5S rRNA gene spacer & 71 & $3(4 \cdot 2)$ & $1(1 \ddagger)$ & $3(3 \ddagger)$ \\
5S rRNA_1 gene & 115 & $7(6 \cdot 1)$ & & - \\
5S rRNA_2 gene & 115 & $8(7 \cdot 0)$ & - & - \\
5S rRNA_1 gene-UU114 spacer\$ & 136 & $31(3 \cdot 8)$ & - & - \\
5S rRNA_2 gene-UU304 spacer\$ & 105 & $20(19 \cdot 0)$ & & - \\
\end{tabular}

${ }^{\star} U$. parvum and $U$. urealyticum interspecies heterogeneity sites were determined independently of intraspecies heterogeneity sites.

$\dagger$ Length modification was based upon two other mollicutes 16S rRNA genome annotations (Fraser et al., 1995; Himmelreich et al., 1996), especially considering Mycoplasma pneumoniae annotation (Himmelreich et al., 1996).

$¥$ Numbers in parentheses were assumed numbers to contain inter-copy heterogeneity (see text for further explanation).

\$The rRNA gene cluster (or 5S rRNA gene) downstream external spacer regions. 
U. urealyticum serovar 13 EF-Tu gene (tuf). Previous studies have shown that differences in tuf can distinguish species and may reflect some phenotypic relationships better than the 16S rRNA gene (Kamla et al., 1996). EFTu gene (tuf) DNA sequences were the same in serovars within each species, except for that of serovar 13 of $U$. urealyticum. It contains two base differences (but the same amino acid sequences) compared with the other nine U. urealyticum serovars (Fig. C in IJSEM Online). This difference is of interest in view of another reported difference between serovar 13, which gives an intermediate response in the $\mathrm{Mn}^{2+}$ (manganese)-inhibition test, and all other $U$. urealyticum serovars, which are fully inhibited (Robertson \& Chen, 1984).

Intraspecies and interspecies heterogeneity of urease gene clusters. There were 21, nine and one intraspecies heterogeneity sites in the urease gene cluster DNA sequences for $U$. parvum serovars 1, 6 and 14 (compared with serovar 3 ), respectively. There were seven heterogeneity sites (or $12 \mathrm{bp}$ - one site has $6 \mathrm{bp}$ difference) in $U$. urealyticum serovar 2, compared with all other $U$. urealyticum serovars. These results show greater heterogeneity between urease gene clusters of $U$. parvum serovars than between those of $U$. urealyticum serovars, as we found previously for $m b a$ (Kong et al., 1999a).

Interspecies heterogeneity between urease gene clusters of the two species was greater in the intergenic spacer regions (where it varies from 16.8 to $31.8 \%$ ) than in the genes themselves (where the range of heterogeneity is 5.9 to $9 \cdot 7 \%)$. Variation in amino acid sequences, between species, is less (range 0.97 to $6.7 \%$ ) than in nucleic acid sequences of urease genes (see supplementary Table A in IJSEM Online).

The 'molecular clock' is different for different $m b a$ regions. As we described previously, different $m b a$ regions apparently evolve at different rates, i.e. according to different 'molecular clocks' (Bromham \& Penny, 2003). The upstream regions are more heterogeneous than $m b a$ itself (Kong et al., 1999a) and the repetitive regions are more heterogeneous than the $5^{\prime}$ end regions. This should be taken into account when using different regions to infer the phylogeny (Kong et al., 1999a).

Indels. Analysis of insertions and deletions (indels) is a very useful tool with which to study bacterial phylogeny (Britten et al., 2003; Gupta \& Griffiths, 2002). We compared the distribution of indels in the four 'core' genes/ gene clusters of four $U$. parvum serovars with those of ten $U$. urealyticum serovars (Figs B, C and D in IJSEM Online) (Kong et al., 2000b). All indels were consistent between serovars within each species, which strongly supports the separation of Ureaplasma species based on indels. The rRNA gene cluster of $U$. parvum differed from that of $U$. urealyticum as follows: (a) a TGTG insertion in the 16S rRNA gene; (b) an AT (for operon 1) or A and C (for operon 2) deletion and AT insertion (for operons 1 and 2) in the 16S-23S rRNA intergenic spacer region; (c) a $G$ insertion in 23S-5S rRNA intergenic spacer region; and (d) a TTAGG (for operon 1) or AAAAA (for operon 2) deletion in the 5S rRNA gene (Fig. B in IJSEM Online). There were no indels in the EF-Tu gene (tuf) (Fig. $\mathrm{C}$ in IJSEM Online). In the urease gene clusters, there were: (a) a TCAAT deletion in the ureA-ureB spacer; (b) AAC, T and CTA insertions in the ureB-ureC spacer; (c) a CA deletion in the ureC-ureE spacer; and (d) an ACATT insertion in the ureF-ureG spacer (Fig. D in IJSEM Online).

Despite these specific differences, the numbers of insertions or deletions, sites and total number of bases in these three genes were not significantly different between the two species. In $m b a$, there were no indels in species-specific sites, but there was an AAATT insertion, an AA deletion, a 45 bp deletion and a TC deletion in U. parvum upstream of mba (Kong et al., 2000b).

\section{Genes, intergenic spacers or gene clusters?}

Many studies have shown that intergenic spacer regions are more heterogeneous than the neighbouring genes (Garcia-Martinez et al., 1999; Kong et al., 1999b). Our study confirmed this by showing greater heterogeneity in the intergenic spacers, especially the external spacer regions, of both the rRNA gene clusters and the urease gene cluster compared with the corresponding genes (see Table 2 and supplementary Figs A, B and D and Table A in IJSEM Online) (Jung et al., 2003). In addition, for urease gene clusters and $m b a$, indels only existed in the gene spacer regions. Because the gene cluster as a whole is a functional group, we suggest that there are a couple of advantages in considering them as a unit in basic and applied research. (i) Whole gene clusters contain both conserved and variable sequences and phylogenetic data derived from them are stable and discriminatory (Gürtler, 1999), which is valuable in solving taxonomic problems (Harasawa, 1999). (ii) Species-specific primer pairs based on whole gene clusters are generally more specific and easier to design than primers based on any single component (Kong et al., 2000a).

\section{DNA or protein sequence? Which protein or gene region?}

To fulfil polyphasic theory requirements (Vandamme et al., 1996), DNA sequences and protein amino acid sequences should be considered together (Agosti et al., 1996). However, DNA sequences often reflect the phylogeny more accurately and have greater (about double) discriminatory power (Simmons et al., 2002). Our study showed that the $m b a$ species-specific region ( $5^{\prime}$ end) DNA (67/ $430=15 \cdot 6 \%)$ and the corresponding amino acid sequences $(24 / 147=16 \cdot 3 \%)$ have nearly identical levels of heterogeneity (Kong et al., 2000b). However, urease gene subunit (Table A in IJSEM Online) and EF-Tu gene DNA sequences are more heterogeneous than their corresponding protein 
amino acid sequences (Fig. C in IJSEM Online). For example, for the ureaplasma EF-Tu gene, DNA sequence heterogeneity was 54 out of $1185(4 \cdot 6 \%)$ bases compared with 2 out of $394(0.5 \%)$ differences in amino acids between the two species. Presumably, genetic changes that significantly alter the structure, and therefore the function, of proteins such as enzymes are incompatible with survival. On the other hand, genetic variation that causes antigenic variation in multiple-banded antigens is not only consistent with survival but also an advantage if it helps the organism to evade the host immune response.

Many surface protein antigen genes are used to study the phylogeny of different microbes and to develop practical identification and typing schemes (Bush \& Everett, 2001; Stackebrandt et al., 2002). Sometimes, the gene or even the gene region selected can significantly affect the results (Bromham \& Penny, 2003). For example, ureaplasma $m b a$ contains both species-specific ( $5^{\prime}$ end region) and serovar definition sites (repetitive regions or $3^{\prime}$ end). Thus, the $5^{\prime}$ end region would be the appropriate region for studying species-level phylogeny, rather than the repetitive regions (Zheng et al., 1995). If different bacterial species share almost identical protein antigens as a result of lateral gene transfer (Lawrence, 2002) - for example, the Streptococcus agalactiae Alp3 protein and Streptococcus pyogenes R28 protein (Stalhammar-Carlemalm et al., 1999) - the corresponding genes lose their value for studying species-level taxonomy (Thornton, 2002).

\section{Why 'core' genes?}

Of the two Ureaplasma species discussed herein - U. parvum and U. urealyticum (Robertson et al., 2002) - a full genome sequence was available only for $U$. parvum (Glass et al., 2000). In future, our understanding of human ureaplasmas would be significantly improved by availability of the full genome sequence of $U$. urealyticum also. In particular, it would help to elucidate the nature and significance of the $>80 \mathrm{kbp}$ size difference between the two human Ureaplasma species (Robertson et al., 1990; Fraser et al., 2000) in reverse evolution (Rocha \& Blanchard, 2002) and pathogenesis (Povlsen et al., 2002). Meanwhile, alternative strategies such as analysis of selected 'core' genes or gene clusters (as in this study) can be used to infer the phylogenetic relationship between species (Daubin et al., 2002). The rationale for the choice of these four genes was that the rRNA gene cluster (Stackebrandt et al., 2002) and tuf (Kamla et al., 1996) have been widely accepted targets for phylogenetic/taxonomic studies and the urease gene cluster and $m b a$ are unique determinants (Stackebrandt et al., 2002) of ureaplasma metabolism (Neyrolles et al., 1996) and antigenicity (Zheng et al., 1995).

\section{Conclusion}

Analysis of four 'core' genes/gene clusters further supported the establishment of two separate human Ureaplasma species - U. parvum and U. urealyticum. Significant differences between genes/gene clusters in the degree of heterogeneity between and within species sheds further light on the relationships between them and makes a useful case study to help understand common problems in the use of sequence data to infer phylogeny and support taxonomic change (Ludwig et al., 1998).

\section{ACKNOWLEDGEMENTS}

We wish to thank M. Wheeler for his precious help in sequencing.

\section{REFERENCES}

Agosti, D., Jacobs, D. \& DeSalle, R. (1996). On combining protein sequences and nucleic acid sequences in phylogenetic analysis: the homeobox protein case. Cladistics 12, 65-82.

Baier, R. J., Loggins, J. \& Kruger, T. E. (2003). Failure of erythromycin to eliminate airway colonization with Ureaplasma urealyticum in very low birth weight infants. BMC Pediatr 3, 10.

Britten, R. J., Rowen, L., Williams, J. \& Cameron, R. A. (2003). Majority of divergence between closely related DNA samples is due to indels. Proc Natl Acad Sci U S A 100, 4661-4665.

Bromham, L. \& Penny, D. (2003). The modern molecular clock. Nat Rev Genet 4, 216-224.

Bush, R. M. \& Everett, K. D. E. (2001). Molecular evolution of the Chlamydiaceae. Int J Syst Evol Microbiol 51, 203-220.

Clayton, R. A., Sutton, G., Hinkle, P. S., Jr, Bult, C. \& Fields, C. (1995). Intraspecific variation in small-subunit rRNA sequences in GenBank: why single sequences may not adequately represent prokaryotic taxa. Int J Syst Bacteriol 45, 595-599.

Daubin, V., Gouy, M. \& Perriere, G. (2002). A phylogenomic approach to bacterial phylogeny: evidence of a core of genes sharing a common history. Genome Res 12, 1080-1090.

Daxboeck, F., Iro, E., Tamussino, K., Krause, R., Assadian, O. \& Wenisch, C. (2003). Bacteremia with Mycoplasma hominis and Ureaplasma urealyticum in patients undergoing hysterectomy. Eur J Clin Microbiol Infect Dis 22, 608-611.

Dellaglio, F., Felis, G. E. \& Germond, J.-E. (2004). Should names reflect the evolution of bacterial species? Int J Syst Evol Microbiol 54, 279-281.

Fraser, C. M., Gocayne, J. D., White, O. \& 7 other authors (1995). The minimal gene complement of Mycoplasma genitalium. Science 270, 397-403.

Fraser, C. M., Eisen, J., Fleischmann, R. D., Ketchum, K. A. \& Peterson, S. (2000). Comparative genomics and understanding of microbial biology. Emerg Infect Dis 6, 505-512.

Garcia-Martinez, J., Acinas, S. G., Anton, A. I. \& RodriguezValera, F. (1999). Use of the $16 \mathrm{~S}-23 \mathrm{~S}$ ribosomal genes spacer region in studies of prokaryotic diversity. J Microbiol Methods 36, $55-64$.

Glass, J. I., Lefkowitz, E. J., Glass, J. S., Heiner, C. R., Chen, E. Y. \& Cassell, G. H. (2000). The complete sequence of the mucosal pathogen Ureaplasma urealyticum. Nature 407, 757-762.

Gupta, R. S. \& Griffiths, E. (2002). Critical issues in bacterial phylogeny. Theor Popul Biol 61, 423-434.

Gürtler, V. (1999). The role of recombination and mutation in 16S23S rDNA spacer rearrangements. Gene 238, 241-252.

Gürtler, V. \& Mayall, B. C. (2001). Genomic approaches to typing, taxonomy and evolution of bacterial isolates. Int J Syst Evol Microbiol 51, 3-16. 
Harasawa, R. (1999). Genetic relationships among mycoplasmas based on the 16S-23S rRNA spacer sequence. Microbiol Immunol 43, 127-132.

Himmelreich, R., Hilbert, H., Plagens, H., Pirkl, E., Li, B. C. \& Herrmann, R. (1996). Complete sequence analysis of the genome of the bacterium Mycoplasma pneumoniae. Nucleic Acids Res 24 4420-4449.

Jung, H. Y., Miyata, S., Oshima, K. \& 7 other authors (2003). First complete nucleotide sequence and heterologous gene organization of the two rRNA operons in the phytoplasma genome. DNA Cell Biol 22, 209-215.

Kamla, V., Henrich, B. \& Hadding, U. (1996). Phylogeny based on elongation factor Tu reflects the phenotypic features of mycoplasmas better than that based on 16S rRNA. Gene 171, 83-87.

Knox, C. L., Giffard, P. \& Timms, P. (1998). The phylogeny of Ureaplasma urealyticum based on the mba gene fragment. Int J Syst Bacteriol 48, 1323-1331.

Kong, F., James, G., Ma, Z., Gordon, S., Bin, W. \& Gilbert, G. L. (1999a). Phylogenetic analysis of Ureaplasma urealyticum - support for the establishment of a new species, Ureaplasma parvum. Int J Syst Bacteriol 49, 1879-1889.

Kong, F., Zhu, X., Wang, W., Zhou, X., Gordon, S. \& Gilbert, G. L. (1999b). Comparative analysis and serovar-specific identification of multiple-banded antigen genes of Ureaplasma urealyticum biovar 1 . J Clin Microbiol 37, 538-543.

Kong, F., Ma, Z., James, G., Gordon, S. \& Gilbert, G. L. (2000a). Species identification and subtyping of Ureaplasma parvum and Ureaplasma urealyticum using PCR-based assays. J Clin Microbiol 38, 1175-1179.

Kong, F., Ma, Z., James, G., Gordon, S. \& Gilbert, G. L. (2000b). Molecular genotyping of human Ureaplasma species based on multiple-banded antigen (MBA) gene sequences. Int $J$ Syst Evol Microbiol 50, 1921-1929.

Lawrence, J. G. (2002). Gene transfer in bacteria: speciation without species? Theor Popul Biol 61, 449-460.

Ludwig, W., Strunk, O., Klugbauer, S., Klugbauer, N., Weizenegger, M., Neumaier, J., Bachleitner, M. \& Schleifer, K. H. (1998). Bacterial phylogeny based on comparative sequence analysis. Electrophoresis 19, 554-568.

Mougel, C., Thioulouse, J., Perrière, G. \& Nesme, X. (2002). A mathematical method for determining genome divergence and species delineation using AFLP. Int J Syst Evol Microbiol 52, 573-586.

Murray, R. G. E. \& Schleifer, K. H. (1994). Taxonomic notes: a proposal for recording the properties of putative taxa of procaryotes. Int J Syst Bacteriol 44, 174-176.

Mygind, T., Birkelund, S. \& Christiansen, G. (1998). DNA sequencing reveals limited heterogeneity in the $16 \mathrm{~S}$ rRNA gene from the $r r n B$ operon among five Mycoplasma hominis isolates. Int J Syst Bacteriol 48, 1067-1071.

Neyrolles, O., Ferris, S., Behbahani, N., Montagnier, L. \& Blanchard, A. (1996). Organization of Ureaplasma urealyticum urease gene cluster and expression in a suppressor strain of Escherichia coli. J Bacteriol 178, 2725.

Pettersson, B., Leitner, T., Ronaghi, M., Bolske, G., Uhlen, M. \& Johansson, K. E. (1996). Phylogeny of the Mycoplasma mycoides cluster as determined by sequence analysis of the $16 \mathrm{~S}$ rRNA genes from the two rRNA operons. J Bacteriol 178, 4131-4142.

Pettersson, B., Tully, J. G., Bölske, G. \& Johansson, K.-E. (2000). Updated phylogenetic description of the Mycoplasma hominis cluster (Weisburg et al. 1989) based on $16 \mathrm{~S}$ rDNA sequences. Int J Syst Evol Microbiol 50, 291-301.

Povlsen, K., Bjornelius, E., Lidbrink, P. \& Lind, I. (2002). Relationship of Ureaplasma urealyticum biovar 2 to nongonococcal urethritis. Eur J Clin Microbiol Infect Dis 21, 97-101.

Robertson, J. A. \& Chen, M. H. (1984). Effects of manganese on the growth and morphology of Ureaplasma urealyticum. J Clin Microbiol 19, 857-864.

Robertson, J. A., Pyle, L. E., Stemke, G. W. \& Finch, L. R. (1990). Human ureaplasmas show diverse genome sizes by pulsed-field electrophoresis. Nucleic Acids Res 18, 1451-1455.

Robertson, J. A., Stemke, G. W., Davis, J. W., Jr, Harasawa, R., Thirkell, D., Kong, F., Shepard, M. C. \& Ford, D. K. (2002). Proposal of Ureaplasma parvum sp. nov. and emended description of Ureaplasma urealyticum (Shepard et al. 1974) Robertson et al. 2001. Int J Syst Evol Microbiol 52, 587-597.

Rocha, E. P. \& Blanchard, A. (2002). Genomic repeats, genome plasticity and the dynamics of mycoplasma evolution. Nucleic Acids Res 30, 2031-2042.

Simmons, M. P., Ochoterena, H. \& Freudenstein, J. V. (2002). Amino acid vs. nucleotide characters: challenging preconceived notions. Mol Phylogenet Evol 24, 78-90.

Stackebrandt, E., Frederiksen, W., Garrity, G. M. \& 10 other authors (2002). Report of the ad hoc committee for the re-evaluation of the species definition in bacteriology. Int J Syst Evol Microbiol 52, 1043-1047.

Stalhammar-Carlemalm, M., Areschoug, T., Larsson, C. \& Lindahl, G. (1999). The R28 protein of Streptococcus pyogenes is related to several group B streptococcal surface proteins, confers protective immunity and promotes binding to human epithelial cells. Mol Microbiol 33, 208-219.

Thornton, J. (2002). Gene family phylogenetics: tracing protein evolution on trees. EXS 92, 191-207.

Ueda, K., Seki, T., Kudo, T., Yoshida, T. \& Kataoka, M. (1999). Two distinct mechanisms cause heterogeneity of $16 \mathrm{~S}$ rRNA. J Bacteriol 181, 78-82.

Vandamme, P., Pot, B., Gillis, M., de Vos, P., Kersters, K. \& Swings, J. (1996). Polyphasic taxonomy, a consensus approach to bacterial systematics. Microbiol Rev 60, 407-438.

Zheng, X., Teng, L. J., Watson, H. L., Glass, J. I., Blanchard, A. \& Cassell, G. H. (1995). Small repeating units within the Ureaplasma urealyticum $\mathrm{MB}$ antigen gene encode serovar specificity and are associated with antigen size variation. Infect Immun 63, 891-898. 